\title{
Changes in a SWI4,6-DNA-binding complex occur at the time of $H O$ gene activation in yeast
}

\author{
M. Rita M. Taba, Ivor Muroff, David Lydall, Graham Tebb, and Kim Nasmyth \\ Research Institute of Molecular Pathology, A-1030 Vienna, Austria
}

The yeast $H O$ gene is transcribed transiently during $G_{1}$ as cells undergo START. START-specific $H O$

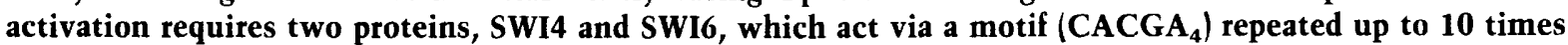
within the URS2 region of the $\mathrm{HO}$ promoter. We identified a DNA-binding activity containing SWI4 and SWI6 that recognizes the CACGA 4 sequences within URS2. Two forms of SWI4,6-DNA complexes called $L$ and $U$ can be distinguished by their electrophoretic mobility. $L$ complexes can be detected at all stages of the cell cycle, but $U$ complexes are only detected in cells that have undergone START. The formation of U complexes may be the trigger of $H O$ activation. The SWI6 protein is concentrated in the nucleus throughout $\mathrm{G}_{1}$, but at some point in $S$ or $G_{2}$ significant amounts accumulate in the cytoplasm. This change in cellular location of the SWI6 protein might contribute to the turnoff of $\mathrm{HO}$ trancription after cells have undergone START.

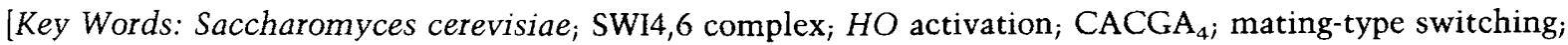
START-dependent transcription]

Received May 9, 1991; revised version accepted August 26, 1991.

During balanced growth, every component of a cell must be duplicated during the course of a single cell cycle. For most components, particularly those that exist in large numbers in a cell \{e.g., ribosomes\}, the process of duplication takes place gradually throughout the cell cycle. In contrast, the duplication of rarer structures, such as chromosomes, takes place at a discrete time. A key question in cell cycle control is how the discontinuous events of the cell cycle (e.g., DNA replication, mitosis, and cytokinesis) take place in the correct order.

It is widely assumed, but by no means proven, that cell cycle stage-specific gene expression is an important means of ordering cell cycle events. Though it is not known to what extent stage-specific gene expression determines the order of the cell cycle events, it is known, for example, that many of the genes for enzymes involved in DNA replication are only transcribed as cells approach S phase (Storms et al. 1984; Peterson 1985; Johnston et al. 1987; White 1987).

One way of addressing the role of cell-cycle-regulated gene expression during the cell cycle is to identify the genes for proteins that are involved in cell cycle-specific gene activation and then characterize the phenotypes of mutants in such genes. One would like to know, for example, the immediate consequences on cell cycle progression following the inactivation of such a protein.

Possibly the best example of such a genetic approach concerns the $H O$ gene in the yeast Saccharomyces cerevisiae (Winge and Roberts 1949; Hawthorne 1963). HO encodes an endonuclease whose pattern of expression determines a well-defined pedigree of mating-type switching (Nasmyth and Shore 1987). HO transcription is confined to a small window in the cell cycle during late $G_{1}$ (Nasmyth 1983 ) and is dependent on the commitment of the cell to $S$ phase, a process known as START, which is dependent on the CDC28 gene product (Hartwell 1974; Pringle and Hartwell 1981). In addition to cell cycle control, $\mathrm{HO}$ is also regulated by the matingtype locus (Jensen et al. 1983) and is only expressed in mother cells (Nasmyth 1983). The HO promoter is large (up to $1500 \mathrm{bp}$; Nasmyth 1985a) and complex, containing at least three different types of control element. A simple and highly specific regulatory sequence, the CACGA 4 repeat, is sufficient to produce START-dependent transcription when joined to the cytochrome $c$ TATA box (Breeden and Nasmyth 1987a). The URS2 region of the promoter (from - 150 to $-900 \mathrm{bp}$ ) contains 10 copies of the repeat; removal of the repeats causes the promoter to become START independent during $G_{1}$ (Nasmyth $1985 \mathrm{~b})$.

At least six different genes, SWI1-SWI6, are required for efficient $H O$ expression (Haber and Garvik 1977; Stern et al. 1984, Breeden and Nasmyth 1987a); however, of these, only SWI4 and SWI6 are required for expression specifically mediated by the $\mathrm{CACGA}_{4}$ repeat (Breeden and Nasmyth 1987a; Andrews and Herskowitz 1989a). It is therefore possible that the cell cycle START dependence of the promoter during $G_{1}$ may be exclusively a result of changes that occur to SWI4 or SWI6 proteins as cells undergo START. Strains with null alleles of SWI4 
(Sockanathan et al. 1991) and SWI6 (Breeden and Nasmyth 1987a) are viable, but double mutants are not, suggesting that these proteins also activate genes that, unlike $H O$, are essential for cell division. The SWI4 protein has been shown to be a component of a DNA-protein complex formed on $\mathrm{CACGA}_{4}$ repeats in vitro, suggesting that it may be a sequence-specific DNA-binding protein (Andrews and Herskowitz 1989b).

In this paper we address whether the SWI6 protein also binds to CACGA ${ }_{4}$ sequences and whether cell cycle regulation of a SWI4,6-binding activity may be responsible for the START dependence of $H O$ expression. We show that SWI4 and SWI6 are components of specific complexes on several DNA fragments containing $\mathrm{CACGA}_{4}$ repeats derived from the URS2 region of the $\mathrm{HO}$ promoter, and that the state of these complexes changes during passage through $\mathrm{G}_{1}$ at the time of $H O$ activation.

\section{Results}

SWI6 is a nuclear protein during $G_{1}$

To characterize the role of SWI6 in $H O$ activation, we have raised antibodies against SWI6 protein produced in Escherichia coli (see Materials and methods). Our antiserum is highly specific for SWI6, as it detects a $90-\mathrm{kD}$ protein in a Western blot that is not detectable when extracts are instead prepared from a swi6 deletion strain (see Fig. 1). To determine whether SWI6 is a nuclear protein, we have analyzed the intracellular distribution of SWI6 using the method of indirect in situ immunofluorescence described by Kilmartin and Adams (1984). In an asynchronous wild-type culture, most cells have nuclear staining exclusively, but some cells also have detectable

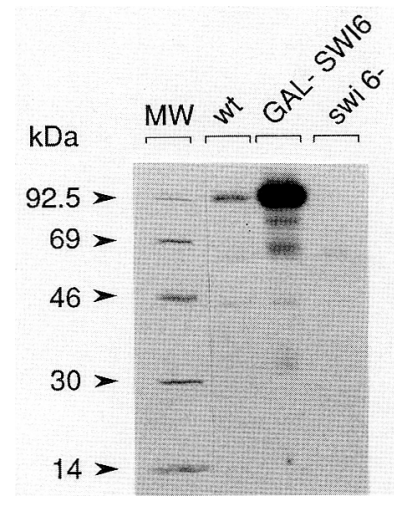

Figure 1. SWI6 is a $90-\mathrm{kD}$ protein. Total yeast cell lysates were prepared from cells grown in YEP-raffinose to exponential phase. Galactose (final concentration, $2 \%$ ) was added to the cultures, and growth was continued for an additional 5-6 hr. Lysates from wild-type cells Y699 (wt), wild-type cells harboring a plasmid containing the SWI6 gene expressed under control of the GAL1-10 promoter (GAL-SWI6) and a strain (Y1748) carrying a $S W I 6$ gene disruption (swi $\left.6^{-}\right)$were chromatographed on a $7.5-20.0 \%$ gradient SDS-PAGE and immunoblotted with antiSWI6 antibodies (at 1: 1000 dilution). Numbers at left indicate migration of molecular mass markers (in kD).

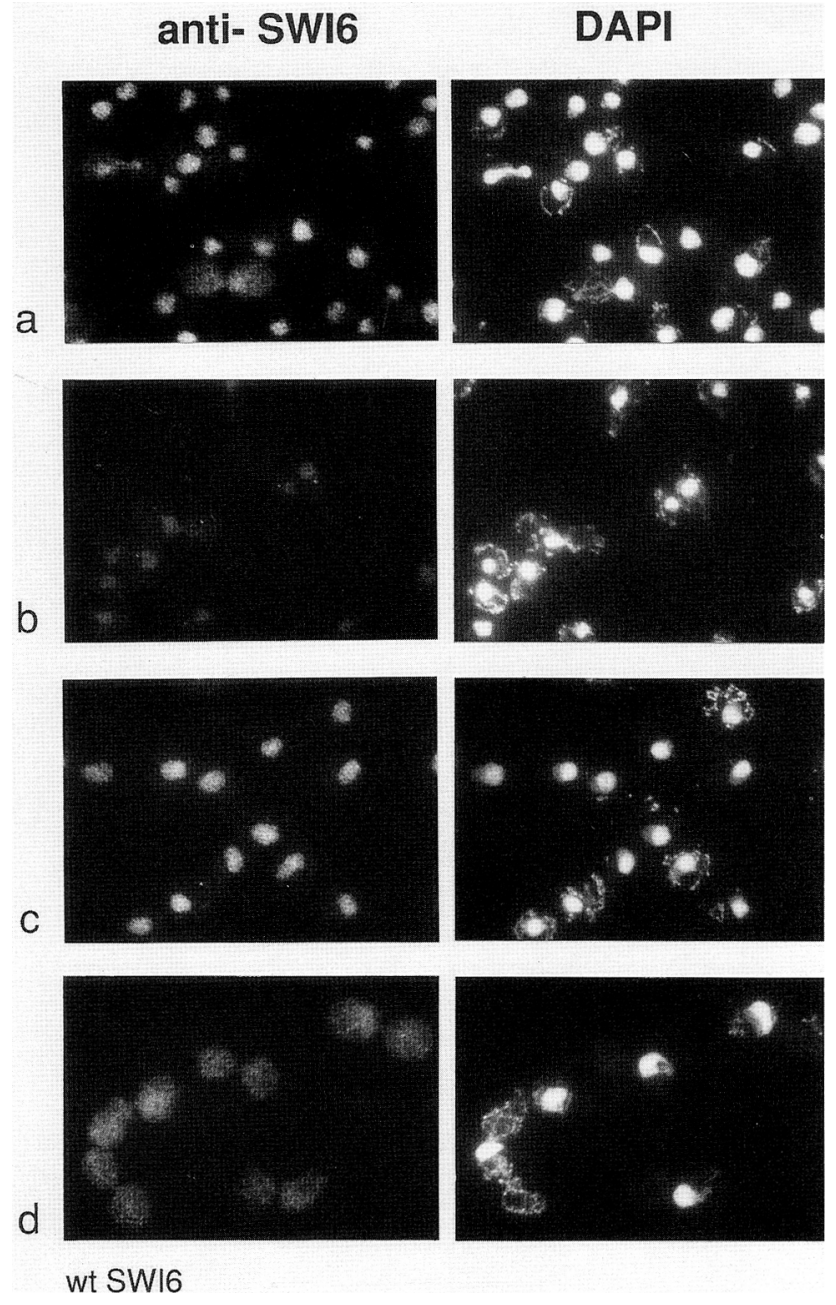

Figure 2. SWI6 is a nuclear protein in $\mathrm{G}_{1}$ cells $/ \alpha$-factor-treated cells) and cytoplasmic in metaphase cells (nocodozole-treated cells). (a) Cells from an asynchronous culture; $(b)$ cells carrying a SWI6 gene disruption; $(c)$ cells treated with $\alpha$-factor; $(d)$ cells treated with nocodozole. Cells were fixed in formaldehyde and treated with rabbit anti-SWI6 antibodies (the primary antibody). SWI6 was visualized with a secondary fluorescein-conjugated anti-rabbit antibody. The weak residual nuclear staining seen in the deletion strain might be the result of the remaining 101 amino acids of the amino terminus of the SWI6 gene product at the deleted locus or the $44-\mathrm{kD}$ protein that weakly cross-reacts in Western blots (see Fig. 1). Nuclei were stained with diamidinophenyl indole (DAPI).

cytoplasmic staining (Fig. 2a). The bulk of this staining must be due to antibodies recognizing SWI6 protein, as much weaker staining is seen in cells containing a partial deletion of the SWI6 gene (Fig. 2b). The heterogeneity of SWI6 staining appears to be a result of cell cycle variation in the distribution of SWI6. All unbudded cells have exclusively nuclear staining, whereas those cells that are about to undergo mitosis (i.e., those in which the nucleus is situated in the neck between mother and daughter and is partially extended) have the additional cytoplasmic staining. To test this idea, cells were syn- 
chronized in early $G_{1}$ with the $\alpha$-factor pheromone (Hartwell 1973) and in mitosis by nocodozole (Jacobs et al. 1988). Figure 2c shows that all $\alpha$-factor-arrested cells have nuclear staining, whereas the nocodazole-arrested cells (Fig. 2d) have mainly cytoplasmic staining. The nuclear membrane does not break down during mitosis in yeast, and other proteins (e.g., RAP1) remain in the nucleus at this stage of the cell cycle (Nasmyth et al. 1990).

We have confirmed and extended these results by expressing SWI6 in various temperature-sensitive cell-division-cycle (cdc) mutants from the GAL1-10 promoter, which produces at least 10 times more protein per cell than the SWI6 promoter (see Fig. 1) and, therefore, a much stronger immunofluorescence signal. Cells arrested in $G_{1}$ as a result of the $c d c 28-4$ mutation have exclusively nuclear staining, cells arrested in $G_{1}$ as a result of a cdc4-1 mutation have mainly nuclear staining, and cells arrested in $G_{1}$ as a result of a cdc7-1 mutation have both nuclear and cytoplasmic staining, whereas cells arrested in $G_{2} / M$ phase by $c d c 13$ or in late anaphase as a result of a $c d c 15$ mutation have predominantly cytoplasmic staining (data not shown). This pattern is similar to that observed for the SWI5 protein (Nasmyth et al. 1990).

The significance of the cell cycle-regulated SWI6 distribution for $H O$ regulation is unclear (see Discussion), but it is important to point out that SWI6 is strongly concentrated in the nucleus at the point during the cell cycle when $H O$ is activated.

\section{SWI6 forms complexes in vitro on fragments of URS2 that contain CACGA 4 motifs}

SWI6 activates $\mathrm{HO}$ via $\mathrm{CACGA}_{4}$ motifs situated in the URS2 region of the $H O$ promoter between -150 and -900 bp (Breeden and Nasmyth 1987a). We would therefore expect that if SWI6 were a DNA-binding protein it would bind specifically to this part of the $H O$ promoter. To test this notion, we used an assay (McKay 1981) that measures the avidity of a protein for different DNA fragments by comparing their ability to be immunoprecipitated by specific antibodies. A pBR322 plasmid containing the entire $H O$ gene plus $1800 \mathrm{bp}$ of $5^{\prime}$-flanking sequences (called pHO; Nasmyth 1985a) was digested with $R s a \mathrm{I}$ or Sau3AI to produce a mixture of 16 or 40 different fragments, respectively. Figure $3 \mathrm{~A}$ shows that of the 16 RsaI fragments only 4 (with sizes of $522,482,318$, and $240 \mathrm{bp}$ ) were selectively precipitated with anti-SWI6 antibodies in the presence of SWI6 protein, and that of the 40 Sau3AI fragments only 3 (with sizes 634,282 , and 131 bp) were similarly precipitated. The selective precipitation of this set of fragments was seen neither when the extracts were made from a swi6 deletion strain (Y1354) nor when preimmune serum was used.

The location of the selectively precipitated fragments within the pHO plasmid is shown in Figure 3C. It is striking that with only one exception all come from the URS2 region of the $H O$ promoter and contain at least

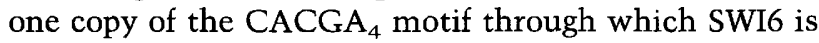
known to act in vivo. The one exception is the 482-bp
RsaI fragment, which covers part of the URS1 region of the promoter. It should also be noted that a 43-bp Sau3AI

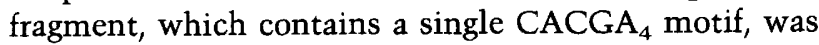
not found enriched in SWI6 immunoprecipitates. We suspect that SWI6 may not bind strongly to this fragment because experiments with a gel retardation assay showed that an oligonucleotide containing these sequences also could not compete with another URS2 fragment (sRS2; see below) for the binding of SWI4,6 complexes (data not shown).

Because the SWI4 gene is also required for activation of $\mathrm{HO}$ via $\mathrm{CACGA}_{4}$ motifs, we have investigated whether the SWI4 protein forms complexes with the same set of fragments that are bound by SWI6. In this case, we have used extracts made from a strain expressing a SWI4-DHFR (dihydrofolate reductase) fusion protein and antibodies directed against DHFR. The results are shown in Figure 3B. A similar restricted set of fragments was selectively precipitated with the anti-DHFR antibodies as with the anti-SWI6 antibodies. Control experiments showed that the selective precipitation was not obtained when the SWI4-DHFR fusion protein was neither present in the extract nor when preimmune serum was used. We therefore conclude that SWI6 binds mainly to the same regions of URS2 as SWI4, although there may be minor differences in the ability of SWI4 DHFR and SWI6 to bind to the 482-bp RsaI fragment. The SWI4-DHFR fusion that we have used lacks the carboxy-terminal part of the SWI4 protein and binds to URS2 fragments even in the absence of SWI6 (data not shown; Sockanathan et al. 1991).

Finally, we have addressed the question of whether the specific binding of SWI6 to fragments of URS2 is cell cycle dependent. Instead of using extracts prepared from an asynchronous log-phase culture, we used extracts from cells with an a-mating type that had been uniformly arrested in early $G_{1}$ by treatment with $\alpha$-factor. The same set of fragments was again selectively precipitated (Fig. 3A), suggesting that SWI6 retains the ability to bind to URS2 during a cell cycle stage in which $\mathrm{HO}$ is not transcribed.

\section{Detection of SWI4,6 complexes on CACGA 4 motifs by using a gel retardation assay}

In the McKay assays, described above, we were unable to detect any cell cycle dependence of the sequence-specific DNA binding by SWI4 or SWI6. However, this assay would not be able to distinguish changes in the physical state of protein-DNA complexes unless such changes caused a detectable difference in the strength of binding. To determine whether minor changes in the conformation of protein-DNA complexes take place during the cell cycle, we have also analyzed such complexes using a gel retardation assay. As a probe, we chose a 90-bp oligonucleotide (called small regulatory sequence from URS2-sRS2) containing DNA sequences from the $\mathrm{HO}$ promoter between -443 and $-358 \mathrm{bp}$ with respect to the translation start site. This region was chosen because it resided within the 240-bp RsaI fragment precipitated 

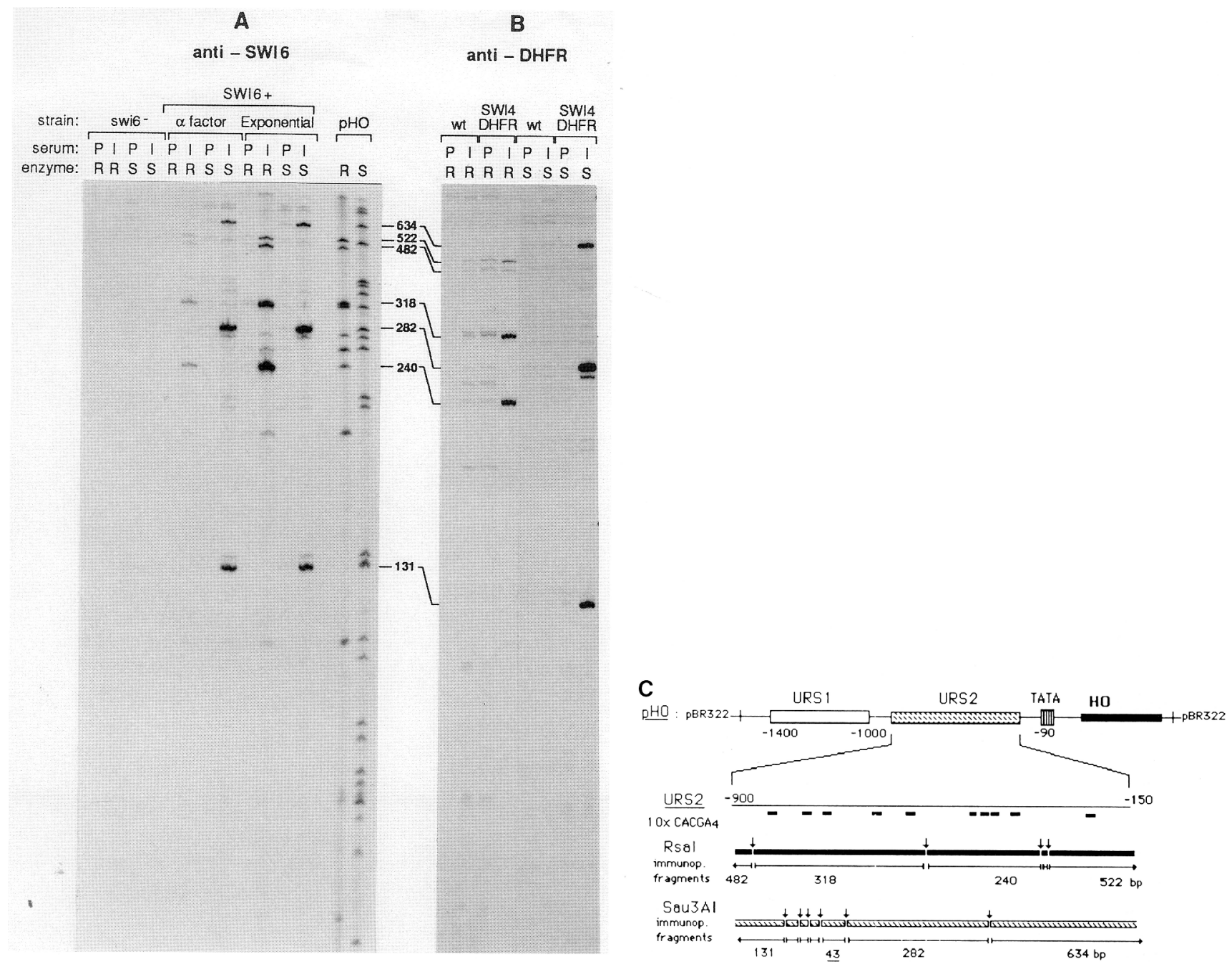

Figure 3. SWI6 and SWI4-DHFR binding to the HO promoter. pHO plasmid containing $1.8 \mathrm{~kb}$ of the $5^{\prime}$-upstream region of $H O$ (Nasmyth 1985b) plus the HO gene was digested either with RsaI or Sau3AI enzymes and end-labeled. These fragments were first incubated with $40 \mu \mathrm{g}$ of yeast crude extracts and subsequently with immune (I) or preimmune antisera (P). Protein A-Sepharose beads were finally added to recover selectively the immunoprecipitated protein-DNA complexes. Those DNA fragments that immunoprecipitated were then analyzed by separation on a $6 \%, 8.3 \mathrm{M}$ urea-polyacrylamide sequencing gel. The molecular sizes of immunoprecipitated DNA fragments are shown (in bp). (A) To detect SWI6-binding activity, extracts were prepared from a $S W I 6^{+}$strain (R1355) and a strain carrying a SWI6 gene disruption (swi6 ${ }^{-}, \mathrm{R} 1354$ ). The SWI6 ${ }^{+}$strain was grown in the absence (exponential) or presence of $\alpha$-factor $(\alpha$-factor $)$ and incubated with immune and pre-immune SWI6 antisera. $(B)$ In the case of SWI4-DHFR-binding activity, a wild-type strain Y1268 (wt) and a wild-type strain harboring a plasmid containing SWI4-DHFR fusion expressed under control of the GAL1-10 promoter (SWI4-DHFR) were incubated with immune and preimmune DHFR antisera. (C) The $5^{\prime}$-upstream DNA of $H O$ and the cleavage sites of RsaI and Sau3AI on the URS2 region of the promoter. (Top) The regulatory elements of the HO promoter and the HO gene cloned into a pBR322 plasmid (pHO) (Nasmyth 1985a). URS1 is required for HO transcription, and URS2 is required for correct cell cycle control. The URS2 region contains 10 copies of a repeat PuNNPyCACGA 4 , the cis-element, which confers the correct cell cycle regulation (Nasmyth 1985b). pHO was digested either with RsaI or Sau3AI, which cleave 16 or 40 different sites, respectively. The URS2 region has four sites for RsaI and six sites for Sau3AI.

in the McKay assay and because it contained four copies

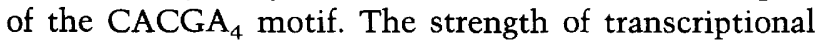
activation by SWI4 and SWI6 seems to be dependent on the number of copies of the $\mathrm{CACGA}_{4}$ motif (Nasmyth 1985b).

Figure 4 shows the pattern of electrophoretic mobility of the radiolabeled sRS2 oligonucleotide in polyacrylamide and agarose gels after incubation with yeast cell extracts. Figure 4A shows that several different types of complexes can be formed on the sRS oligonucleotide; but of these, only two (U for upper and $\mathrm{L}$ and for lower) are competed by unlabeled sRS2 DNA but not by an unrelated oligonucleotide from the URS1 region of the $H O$ promoter. Because both the $\mathrm{U}$ and the $\mathrm{L}$ complexes are also competed by an oligonucleotide composed entirely of multiple copies of the CACGA 4 motif (Fig. 4A), 


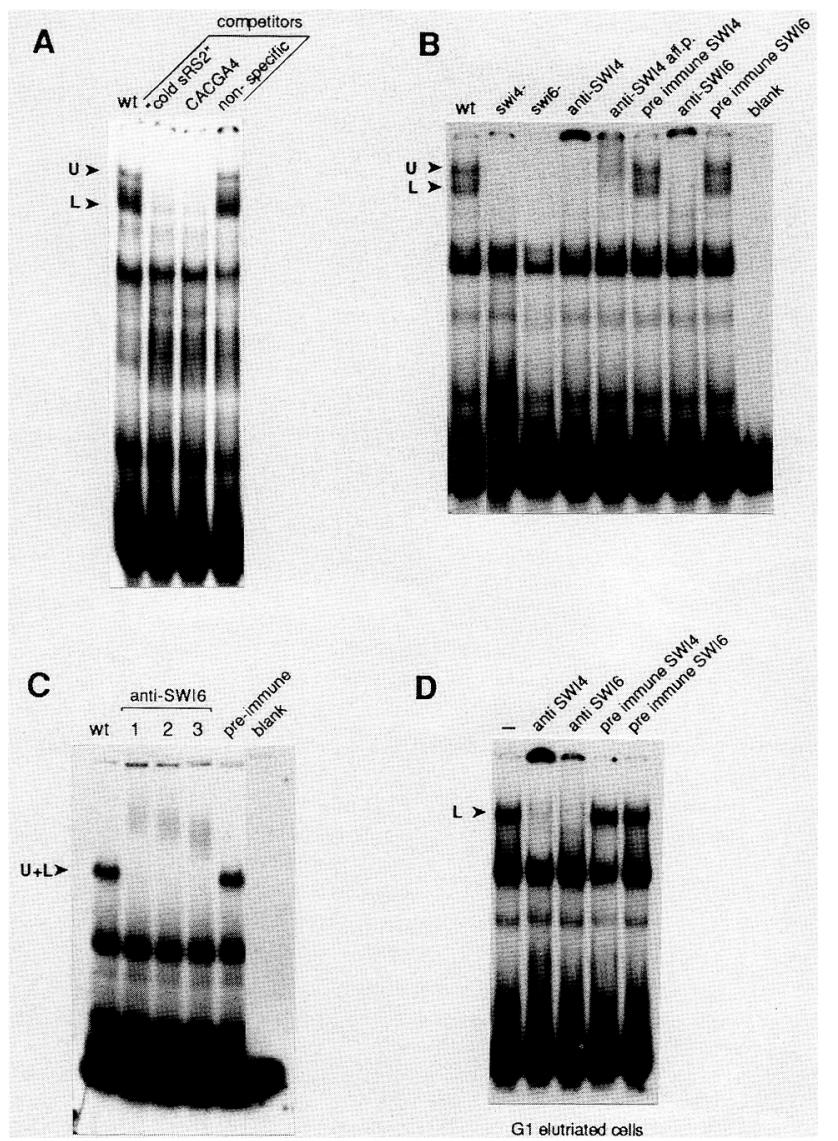

Figure 4. Complexes containing SWI4 and SWI6 form on $\mathrm{CACGA}_{4}$ sequences from URS2. A 90-bp DNA sequence (sRS2) derived from the URS2 region of the $H O$ promoter was radiolabeled and used as a probe in gel retardation assays with crude yeast cell extracts ( $40 \mu \mathrm{g}$ of total protein) as described in Materials and methods. $(A)$ Competition assay. Extract prepared from wild-type strain Y1720 (wt) was assayed with the addition of 100-fold molar excess of oligonucleotide competitors: Unlabeled sRS2 (cold sRs2), an oligonucleotide composed of five copies in tandem of the sequence tcgatcCACGAAAA (CACGA 4 ), and an oligonucleotide containing the SWI5-binding site (nonspecific). (B) U and L complexes contain SWI4 and SWI6. Extracts from swi4 mutants (R1071) or swi6 mutants (R1354) do not form $U$ and $L$ complexes on sRS2 in comparison with wildtype strain Y1268. SWI4 and SWI6 are components of both U or $\mathrm{L}$ complexes, because $\mathrm{U}$ and $\mathrm{L}$ are affected in their migration by incubation with specific antibodies /anti-SWI4, 1:200 dilution; anti-SWI6, $1: 400$ dilution) but not with corresponding preimmune sera. $(C)$ The migration of $U$ and $\mathrm{L}$ complexes is retarded by the addition of anti-SWI6 antibodies. This reaction mixture was electrophoresed in a $1.5 \%$ agarose gel. The migration of a unique band (wt), presumably comigrating $U$ and $L$ complexes, is retarded by the addition of SWI6-specific antibodies. Lanes 1 , 2 , and 3 contain decreasing amounts of anti-SWI6 antibodies (1:200,1:2000, 1:3000 final dilutions) and show complexes with increasing mobility, respectively, as a result of a reduced amount of bound antibodies. $(D) \mathrm{L}$ complexes from early $\mathrm{G}_{1}$ cells contain both SWI4 and SWI6. Small $G_{1}$ cells isolated by centrifugal elutriation form only $\mathrm{L}$ complexes whose electrophoretic mobility is affected either by SWI4-specific or SWI6specific antibodies but not by the corresponding preimmune sera. and because neither can be detected in extracts from swi4 or swi6 mutants (Fig. 4B), we propose that they are the result of the sequence-specific binding of SWI4 and SWI6 to one of the CACGA 4 motifs within the oligonucleotide.

We have confirmed that SWI6 is a component of both the $U$ and $\mathrm{L}$ complexes by showing that both will bind antibodies specific for SWI6 (Fig. 4B-D). The addition of anti-SWI6 antibodies to the binding reaction after mixing the extract and oligonucleotide eliminates both complexes. The antibodies do not prevent the complexes from forming but, rather, produce ternary complexes whose electrophoretic mobility is so reduced that they no longer enter the polyacrylamide gel (Fig. 4B,D). This notion has been confirmed by running the complexes on an agarose gel (Fig. $4 \mathrm{C}$ ) where we see only a single complex that is SWI4- and SWI6-dependent (data not shown) and that is retarded by the addition of SWI6-specific antibodies. (We presume that the $\mathrm{U}$ and $\mathrm{L}$ complexes are not resolved under these conditions and that they comigrate). Andrews and Herskowitz (1989b), using antiSWI4 antibodies, have shown that a similar gel retardation complex contains SWI4 and is dependent on SWI6. This complex is formed on a fragment of URS2 that contains most of the sRS2 oligonucleotide sequence (CCB DNA sequence between -507 and -394 ). Using these same anti-SWI4 antibodies, we show that SWI4 is also a component of both $U$ and $L$ complexes (Fig. 4B,D). We will refer to both as SWI4-SWI6 DNA-binding complexes even though we do not yet know whether SWI4 and SWI6 are the sole protein constituents.

\section{$U$ complex formation is cell cycle dependent}

Because $H O$ is only activated late in $\mathrm{G}_{1}$ after cells have undergone START, we have addressed the question of whether the formation of either the $U$ or the $L$ complex is cell cycle dependent by comparing extracts from an asynchronous population of cycling cells with those prepared from a uniform population of early $G_{1}$ (i.e., preSTART) cells. We have used three different means of producing uniform populations of early $\mathrm{G}_{1}$ cells: growth of $c d c 28-4$ mutant cells at the restrictive temperature (Fig. 5A), treatment of MATa cells with the $\alpha$-factor pheromone (Fig. 5B), and size selection with centrifugal elutriation (Fig. 7A, below). In each case, we have obtained the same result: $U$ complexes are absent from preSTART $G_{1}$ cells, whereas $L$ complexes are present. Like those seen in exponentially growing cells, the $L$ complexes seen in early $\mathrm{G}_{1}$ cells obtained by centrifugal elutriation contain both SWI4 and SWI6 proteins (Fig. 4D). Identical results were obtained with $G_{1}$ cells obtained by $\alpha$-factor treatment or by shifting $c d c 28-4$ mutants to the restrictive temperature (data not shown).

\section{Formation of the $U$ complex occurs at the onset of HO transcription}

The START dependence of the $U$ complex suggests that it might be the transcriptionally active form. To test 


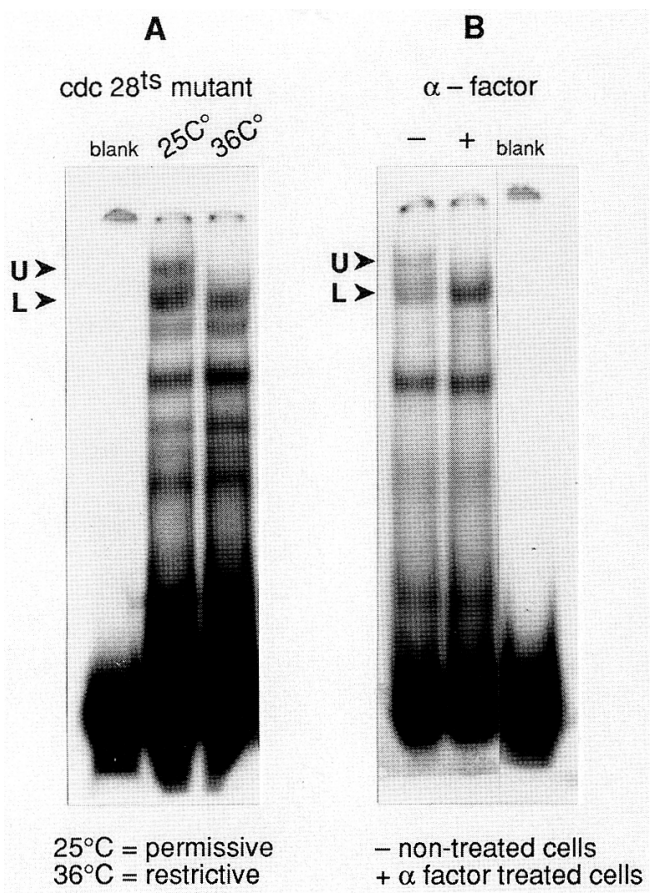

Figure 5. SWI4-SWI6 binding is dependent on completion of START. Gel-retardation assays were performed with crude extracts and sRS2 as a probe. (Blank) The reaction without cell extracts. (A) An exponentially growing culture of $c d c 28-4 \mathrm{mu}$ tant (strain R1719b) was either kept at $25^{\circ} \mathrm{C}$ or shifted to $36^{\circ} \mathrm{C}$ for $2.5 \mathrm{hr}$ before preparing extracts. (B) Wild-type strain (R1355) was grown exponentially in the presence $(2.5 \mathrm{hr})$ or absence of $\alpha$-factor

whether the formation of $U$ complex and the activation of $H O$ are correlated in time, we compared the formation of $\mathrm{U}$ complex and the activation of $\mathrm{HO}$ during the progression of a synchronous culture.

The simplest means of synchronizing the passage of cells through START is to release them from an $\alpha$-factorinduced $G_{1}$ arrest by removal of pheromone from the medium. Unfortunately, the $H O$ gene is not normally expressed during the first cell cycle following such a release (Nasmyth 1983). The probable reason for this is that $H O$ not only requires SWI4 and SWI6 but also another transcription factor called SWI5, which is known to act via the URS1 region of the HO promoter. SWI5 is itself cell cycle regulated and is not expressed throughout the $G_{1}$ period, being activated at some point during $S$ phase (Nasmyth et al. 1987). It has been proposed that the SWI5 inherited from the previous cell cycle is destroyed during the pheromone treatment and that none can be resynthesized between the release from $\alpha$-factor and the onset of START (Nasmyth et al. 1987). We have therefore used a strain (R1793) in our $\alpha$-factor release experiment that is capable of expressing $H O$ during the first cycle following release because SWIS is constitutively expressed throughout the cell cycle.

Cells of strain R1793 were released from an $\alpha$-factorinduced $G_{1}$ arrest by harvesting them by filtration and resuspending them in fresh medium lacking the pheromone. At 5- to 10-min intervals following the release, cell samples were harvested to assay DNA binding, to measure RNA levels, and to score cell cycle stage. The progress of these cells through the cell cycle was highly synchronous, with buds (an approximate indication of cells having initiated $S$ phase) forming at $80 \mathrm{~min}$ and most cells with elongated spindles initiating anaphase between 130 and $150 \mathrm{~min}$, as scored by indirect immunofluorescence with anti-tubulin antibodies (Fig. 6A). Figure $6, B_{1}$ and $B_{2}$, shows the pattern of gel retardation with oligonucleotide sRS2, and Figure $6 \mathrm{C}$ shows the level of $H O$ RNA as measured by $\mathrm{S} 1$ mapping. HO RNAs appear transiently, reaching half-maximal levels between 60 and $65 \mathrm{~min}$ and peaking at $75 \mathrm{~min}$. In contrast, the MATa1 transcript remains at a constant level throughout the experiment. As expected, the starting arrested culture lacks the U complex but it begins to appear by $60 \mathrm{~min}$ (Fig. $\left.6 \mathrm{~B}_{1}\right)$. The appearance of $U$ complexes by $60 \mathrm{~min}$ is seen more clearly after longer electrophoresis (see Fig. $6 \mathrm{~B}_{2}$ ). It seems, therefore, that the appearance of $H O$ RNAs correlates with the appearance of $U$ complexes. Both entities appear in significant amounts by $60 \mathrm{~min}$ (for further discussion, see the legend to Fig. 6).

One of the striking features of the pattern of gel retardation as cells progress through the cell cycle is that whereas the appearance of the $\mathrm{U}$ complexes parallels $\mathrm{HO}$ activation, there is no reciprocal disappearance as the $H O$ promoter is turned off. The ratio of $\mathrm{U}$ to $\mathrm{L}$ complex seems to increase until it reaches a maximum at 110$130 \mathrm{~min}$, by which time $H O$ is no longer transcribed.

Another notable aspect of this experiment is that there is apparently no loss of the $U$ complex as cells enter $G_{1}$ in the second cell cycle following release. Data from three different methods suggest that the $U$ complex is absent in early $G_{1}$ cells that have not yet undergone START (see Figs. 5 and 7A); we would therefore also expect to see a loss of $U$ complexes as cells released from the $\alpha$-factor block reenter $G_{1}$ following mitosis. Our explanation for this apparent contradiction is that cells synchronized by the method of $\alpha$-factor release are much larger than normal as a result of cell growth while arrested in $G_{1}$, and as a consequence they undergo START very soon after completing mitosis; that is, such cells have a very short pre-START $G_{1}$ period in the second cell cycle-the only period during which the cells should lack $U$ complexes. A loss of $U$ complexes will therefore be difficult to detect if synchrony is not perfect. The ratio of $U$ to $\mathrm{L}$ complex does seem to decrease as cells complete anaphase (see the 150- and 160-min samples in Fig. 6B).

To clarify whether $U$ complexes are absent in $G_{1}$ cells and to investigate further whether their appearance correlates with $H O$ activation, we have analyzed the level of $H O$ transcripts and the electrophoretic mobility of SWI4,6-DNA complexes in cells fractionated according to their size with an elutriation rotor (Fig. 7). An asynchronous culture growing in YEP-galactose (there are too few separated $G_{1}$ cells in glucose-grown cultures) was loaded onto an elutriation rotor, and five fractions 
Taba et al.

composed of cells with increasing size were collected by gradually raising the flow rate (ideally, we would have liked to isolate enough $G_{1}$ cells to make a synchronous culture, but this proved impossible). As in the $\alpha$-factor release experiment, we see a correlation between the level of $\mathrm{U}$ complexes and that of $H O$ transcripts in the five fractions. $H O$ and $U$ complexes are both completely absent in the first fraction; both appear in significant amounts in the third and are maximal in the fourth and fifth fraction. In summary, it is difficult to say conclu- sively from the $\alpha$-factor release and elutriation experiments that $U$ complexes appear early enough for them to be the cause of $H O$ activation, but the data are certainly consistent with this hypothesis.

\section{$U$ complexes in cell cycle mutants}

To confirm the observation that $U$ complexes do not disappear at the time of $H O$ inactivation, we have also assayed the formation of $U$ complex in various temper-

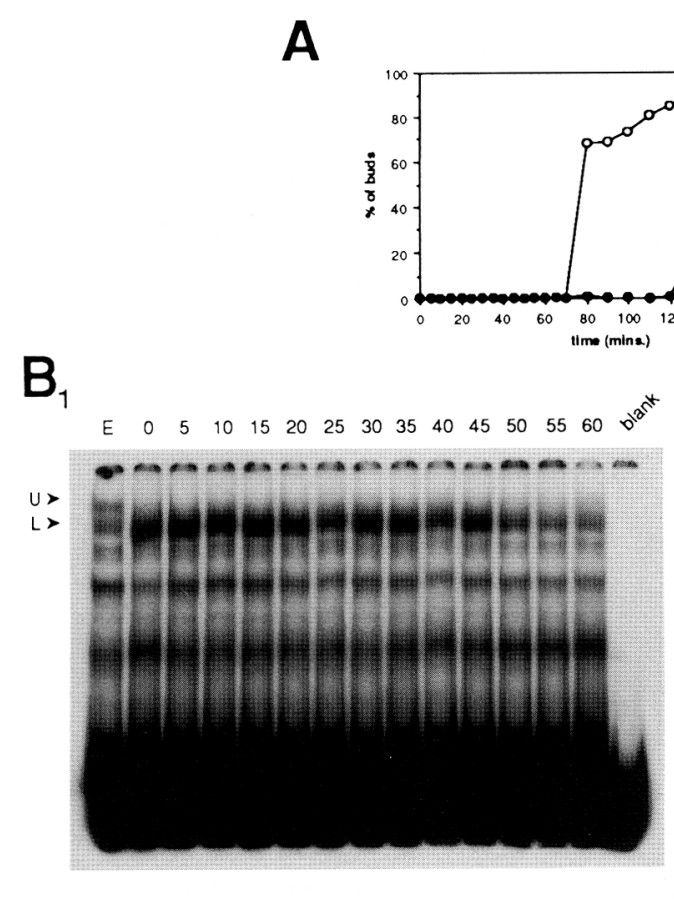

$\mathrm{B}_{2}$
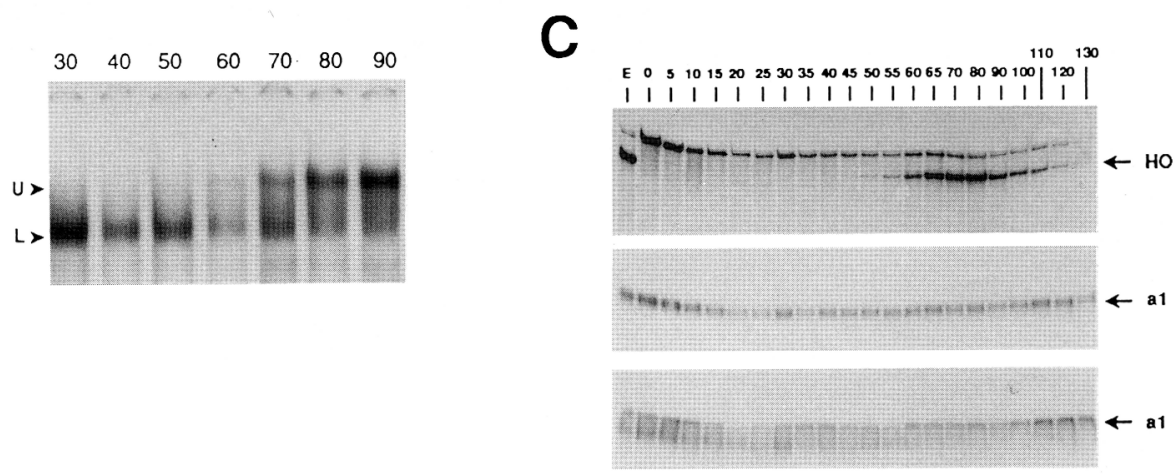

D
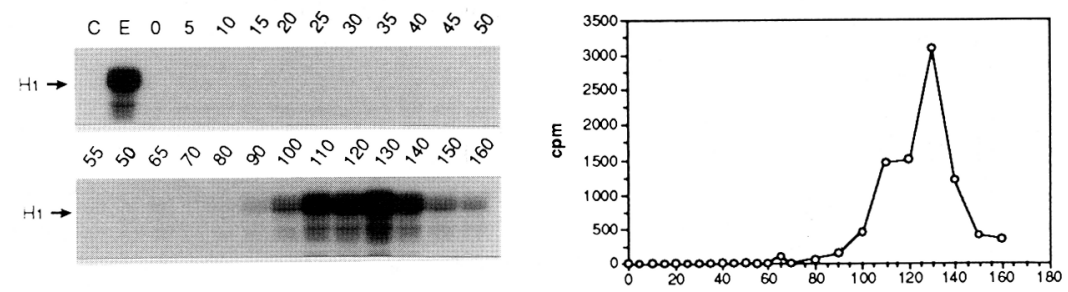

Figure 6. (See facing page for legend.) 
ature-sensitive $c d c$ mutants when their cell cycles are blocked by incubation at the restrictive temperature. Figure $8 \mathrm{~A}$ shows that the $\mathrm{U}$ complex exists in $c d c 4-$, $c d c 7-, c d c 13-$ and $c d c 15$-blocked cells. $c d c 4$ and $c d c 7$ mutations block cells in $\mathrm{G}_{1}$ but do not prevent $H O$ from being activated. The observation that these mutations also do not prevent the formation of $U$ complex is therefore consistent with its playing a role in $\mathrm{HO}$ activation. The observation that $\mathrm{U}$ complexes also exist in $c d c 13$ mutants, which arrest in $\mathrm{G}_{2} / \mathrm{M}$, and cdc15 mutants, which arrest in late anaphase, suggests that the $U$ complex persists until the very end of the cell cycle. Because $H O$ is expressed neither during the $\mathrm{G}_{2}$ period of wildtype cells nor in cells blocked in $\mathrm{G}_{2}$ or anaphase, we conclude that whereas $H O$ activation may be triggered by the formation of $U$ complex, its subsequent inactivation during $\mathrm{S}$ phase is unlikely to be simply the result of the loss of this complex (see Discussion).

\section{In vivo activity of sRS2 during the cell cycle}

To investigate whether SWI4-SWI6 complexes of the type that we have detected in vitro also form in vivo, we have analyzed the in vivo activity of the sRS2 oligonucleotide by fusing it to a form of the CYC1 promoter that lacks an upstream activation sequence (UAS) and is fused to the reporter gene lacZ (see figure legends).

Figure 8B compares the level of lacZ RNAs produced by no UAS (a), by the ribosomal protein gene RP39 UAS (b), and by sRS2 (c). As expected for a sequence that binds SWI4 and SWI6 in vitro, sRS2 exerts appreciable "upstream activation," producing $40 \%$ as much lacZ RNA as RP39. Unlike RP39, the sRS2 activation is completely dependent on SWI4 and SWI6. We presume, therefore, that the SWI4-SWI6 complexes that form in vitro also form in vivo and are capable of transcriptional activation.

To compare the cell cycle dependence of this activation with the abundance of $U$ complexes, we have measured $l a c Z$ transcripts in $c d c 28, c d c 4, c d c 7, c d c 13$, and $c d c 15$ mutants after stationary-phase cells are incubated in fresh medium at the restrictive temperature for $3 \mathrm{hr}$. We find that sRS2 is inactive in cells that cannot undergo START (cdc28), in cells arrested in $\mathrm{G}_{2}(c d c 13)$, and in cells arrested in a late stage of anaphase (cdc15). In contrast, sRS2 is active in mutants that can undergo START but that arrest before the initiation of DNA replication: $c d c 4$ and, to a lesser extent, $c d c 7$. In the case of $c d c 28, c d c 4$, and $c d c 7$, there is a correlation between the ability of cells to form the U complex and sRS2 activity in vivo, but this does not apply to $c d c 13$ and $c d c 15 \mathrm{mu}-$ tants in which $\mathrm{U}$ complex is formed in vitro but $\mathrm{sRS} 2$ is inactive.

\section{Role of CDC28 protein kinase in HO activation}

The activation of $\mathrm{HO}$ and the formation of the $\mathrm{U}$ complex both require an active $C D C 28$ gene product that encodes a protein kinase. It is possible that an activation of the CDC28 protein kinase at some time in $G_{1}$ triggers $H O$ transcription by site specifically phosphorylating SWI4 or SWI6. Surana et al. (1991) have found that a form of the CDC28 kinase that binds to Suc1-Sepharose beads (Brizuela et al. 1987) and uses histone $\mathrm{HI}$ as a substrate is active soon after the onset of $\mathrm{S}$ phase. To address whether this form of the kinase could be involved in $H O$ activation, we have assayed Sucl-bound kinase activity during the course of the synchronous culture described above. Figure 6D confirms that this form of the kinase is highly cell cycle regulated. Histone $\mathrm{H} 1$ phosphorylation is absent in the starting culture of $G_{1}$-blocked cells and only appears in significant amounts $90-100 \mathrm{~min}$ after the release. The kinase activity peaks at $130 \mathrm{~min}$, which is just before the onset of anaphase. It is notable that there is no detectable activity at the time of $\mathrm{HO}$ activation and $\mathrm{U}$ complex formation. We conclude that this form of the CDC28 kinase is unlikely to be responsible for $\mathrm{HO}$ activation, and because the CDC28 gene product is nevertheless required for the onset of $\mathrm{HO}$ expression a second form of the kinase must exist that is active earlier in the cell cycle than the form that we have measured. To determine whether phosphorylation might be responsible

Figure 6. The timing of $U$ complex formation following release from $\alpha$-factor-induced $G_{1}$ arrest. A synchronous culture of strain $\mathrm{R} 1793$ was prepared by releasing cells from a $\mathrm{G}_{1}$ block by treatment with $\alpha$-factor. Samples of cells were harvested at indicated time points, and extracts were prepared for gel-retardation assays and for RNA and CDC28 histone Hl kinase activity analyses. Synchrony was followed both by scoring the bud formation and by measuring cells with elongated spindles by indirect immunofluorescence with anti-tubulin antibodies. (A) Percentage of cells showing bud formation $(O)$ (roughly coincident with $\mathrm{S}$ phase) and elongated spindles -) (i.e., anaphase) after releasing cells from the $\alpha$-factor block. $\left(B_{1}\right)$ Gel-retardation assay using sRS2 as a probe. (E) Extract from asynchronous cells not treated with $\alpha$-factor; (blank) the reaction mix to which no extract was added. $\left(B_{2}\right)$ Samples 30, 40, 50, 60, 70, 80 , and $90 \mathrm{~min}$ reanalyzed in a gel-retardation assay identical to $B_{1}$ but electrophoresed longer. $(C) H O$ RNAs analyzed by Sl protection. MATa1 RNA as an internal control was also mapped. (D) CDC28 histone H1 kinase associated with Sucl beads. (C) No extract added. The graph shows the amount of radioactivity in the histone $\mathrm{Hl}$ band. To compare precisely the kinetics of $H O \mathrm{RNA}$ appearance and $U$ complexes would involve comparing, at different time points, the fraction of cells that had initiated START and HO transcription with the fractions of cells containing $U$ complex form. Imperfect synchrony makes it difficult to assess the former. Much of the apparent duration of $H O$ transcription (from 60 to $100 \mathrm{~min}$ ) is probably a result of asynchrony (i.e, it takes $\sim 30 \mathrm{~min}$ for all cells in the culture to pass through their windows of $H O$ activation). Thus, the appearance of half-maximal $H O$ RNA levels at, e.g., 63 min, cannot be taken to mean that $50 \%$ of the cells have initiated $H O$ transcription. It is also possible that gel retardation to detect $U$ complex formation is a less sensitive assay than S1 mapping to detect $H O$ RNA. Therefore, it would be more difficult to detect the first molecules of the transcriptionally active complex, although they would be sufficient to initiate transcription of detectable amounts of $H O$ RNA. 


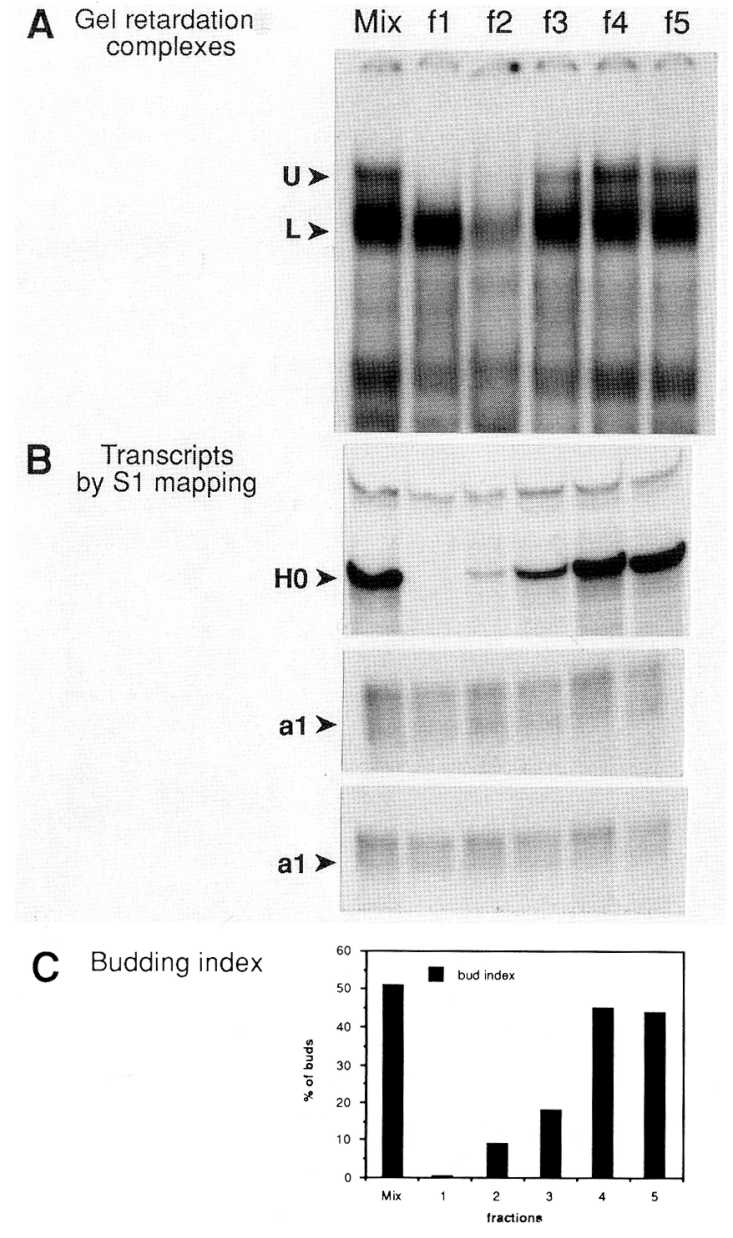

Figure 7. Comparison of the levels of $\mathrm{U}$ complexes and $\mathrm{HO}$ RNA in cells fractionated according to size by centrifugal elutriation. Strain R1793 was exponentially grown in YEP-galactose and at $\mathrm{OD}_{600}=2.5$, loaded into a Beckman JE-10X centrifugal elutriation rotor. Small $G_{1}$ cells were collected initially, followed by subsequent fractions containing increasing numbers of cells with buds. Extracts were prepared for gel-retardation assay and RNAs for mapping $H O$ transcripts by $\mathrm{Sl}$ protection. (A) Gel-retardation assay with sRS2 as a probe. (Mix) Cycling cell population; (fl-f5) successive fractions obtained after the initial $G_{1}$ population. $f 2$ extract shows a weaker signal because of a low yield in the protein extraction procedure (here, we used $25 \mu \mathrm{g}$ of total protein). (B) HO RNAs analyzed by S1 protection. MATa1 RNA as an internal control was also mapped. $(C)$ Percentage of budded cells in each fraction.

for the slower migration of $U$ complexes, we have treated extracts with calf intestinal alkaline phosphatase (CIP) but have found that $\mathrm{U}$ and $\mathrm{L}$ complexes are equally sensitive (data not shown).

\section{Discussion}

In an effort to understand the biochemical basis of START, we and others have been studying the cell cycle regulation of the $H O$ gene (for review, see Herskowitz
1989 |, which is transiently activated as cells undergo START (Nasmyth and Shore 1987). HO encodes an endonuclease that initiates mating-type switching in homothallic strains of yeast (Winge and Roberts 1949; Hawthorne 1963). Its activation is not only dependent on cell cycle stage but also on cell lineage (Nasmyth 1983). $H O$ is activated at START in only one of the two progeny of a cell division-in the mother cell that has just produced a bud. Two separate parts of the $H O$ promoter and distinct trans-acting gene products are responsible for its lineage and cell cycle specificity (Nasmyth 1985a). URS2, the region between -150 and $-900 \mathrm{bp}$, contains a repeated motif, CACGA 4 , which imparts START-dependent activation dependent on two proteins encoded by the SWI4 and SWI6 genes (Nasmyth 1985b; Breeden and Nasmyth 1987a). In contrast, URS1, the region between -1000 and $-1400 \mathrm{bp}$, is implicated in mother cell-specific activation that requires a site-specific DNAbinding protein encoded by the SWI5 gene (Stillman et al. 1988). Cell cycle control of $H O$ is not exclusively the result of URS2. A version of the $H O$ promoter lacking URS2 (called HO::urs2del; Nasmyth et al. 1990) is inactive throughout the $S, G_{2}$, and $M$ phases of the cell cycle because SWI5 is excluded from the nucleus at these stages. HO::urs2del is only activated when the SWI5 protein suddenly enters the nucleus at the end of mitosis. SWI4 and SWI6 (acting via the CACGA 4 repeat in URS2) somehow restrict the $G_{1}$-specific activation of $H O$ exerted by SWI5 to the later part of $\mathrm{G}_{1}$ during which cells undergo START.

In this study we have addressed two questions: Do SWI4 and SWI6 activate $H O$ by binding to the CACGA motifs within URS2? And, if so, is their binding cell cycle-regulated in a manner consistent with this being the mechanism of START-specific $H O$ activation? We have found that antibodies specific to SWI6 immunoprecipitate a restricted set of fragments from an RsaI or Sau3A restriction digest of a pBR322 plasmid containing the $H O$ gene and promoter (Nasmyth 1985b) when they have been preincubated with extracts from wild-type strains but not from swi6 mutants. With only a single exception, the selectively precipitated fragments come from the URS2 region of the promoter and contain $\mathrm{CACGA}_{4}$ motifs. Because a similar set of fragments are also selectively precipitated with anti-DHFR antibodies when the extracts are made from cells expressing a SWI4-DHFR fusion protein, we presume that both SWI4 and SWI6 form complexes on the same CACGA Cotifs. $_{4}$ This conclusion is supported by experiments using gel retardation as an assay of DNA binding. Extracts from wild-type cells form complexes on a 90-bp fragment from URS2 (sRS2), which are specifically competed by an oligonucleotide containing multimers of the $\mathrm{CACGA}_{4}$ motif. Andrews and Herskowitz (1989b) have detected similar complexes on a related DNA sequence and have shown them to contain the SWI4 protein. We have shown that the complexes formed on SRS2 contain both SWI4 and SWI6 proteins as their electrophoretic mobility is retarded further by the binding of SWI4- or SWI6specific antibodies. However, our experiments do not 


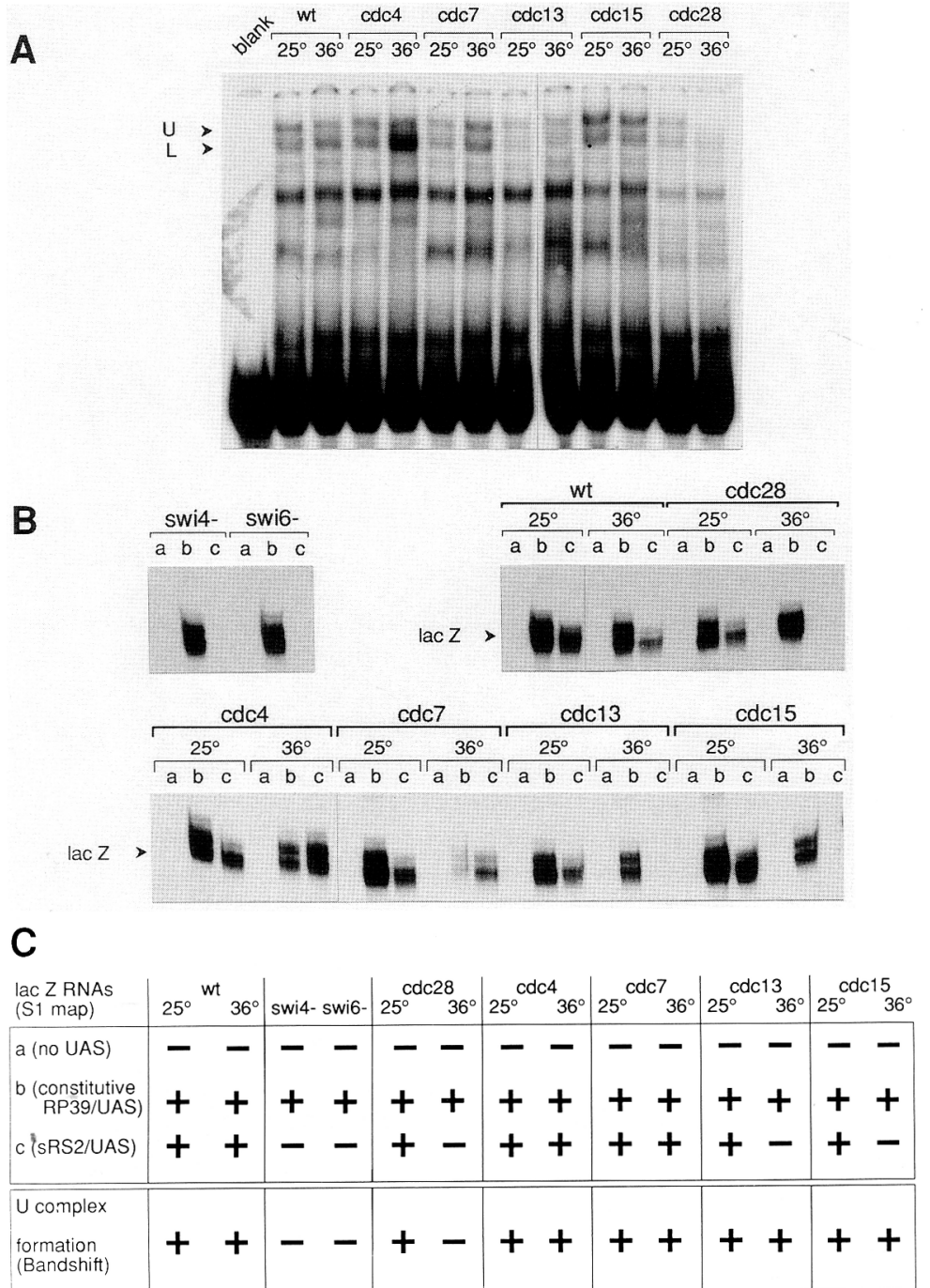

Figure 8. sRS2 DNA can regulate $u b Y-l a c Z$ ।a fusion of the ubiquitin $\mathrm{Y}$ gene to the lacZ gene; Lydall et al., in press|. Expression in a cell cycle-dependent manner. SWI4-SWI6 U complexes correlate with ubY-lacZ transcription activation but not with inactivation. $(A)$ Wildtype strain R1720 and the following cell-division-cycle mutants, cdc4-1 (R1731b), cdc7-1 (R1733b), cdc13 (R1735b), cdc15 (R1728b), and $c d c 28-4$ (R1719b), were grown at $25^{\circ} \mathrm{C}$ to exponential phase and either kept at $25^{\circ} \mathrm{C}$ or shifted to $36^{\circ} \mathrm{C}$ for $3 \mathrm{hr}$. Extracts were prepared from these cells and tested in a gel-retardation assay by using sRS2 as a probe. $(B)$ sRS2 DNA sequence was fused to the CYC promoter lacking a UAS and a reporter gene construct $u b Y-l a c Z$. To measure the ability of sRS2 in activating transcription, we determined $u b Y-l a c Z$ RNA levels in the absence of a UAS (lane $A$ ), in the presence of a constitutive ribosomal protein gene RP39 UAS (lane $B$ ), and in the presence of sRS2 (lane $C$ ). Each of these constructs was integrated as a single copy into the URA3 locus of the following strains: swi4 ${ }^{-}$ (Y1052), swi6- (Y1748), wt (Y699), cdc28-4 (Y1719a), cdc4-1 (Y173la), cdc7-13 (Y1733a), cdc13 (Y1735a), and $c d c 15$ (Y1728a). Cells were grown to exponential phase at $25^{\circ} \mathrm{C}$ and either kept at $25^{\circ} \mathrm{C}$ or shifted to $36^{\circ} \mathrm{C}$ for 3 hr. RNAs were prepared and the $u b Y-l a c Z$ transcript was mapped in all cases by $S 1$ protection. Sample control $c d c 7$ at $36^{\circ} \mathrm{C}$ was partially lost during boiling (lane b). (C) Summary of the results obtained from $u b Y-l a c Z$ RNA measurements and SWI4-SWI6 U-complex formation in wt, swi $4^{-}$, swi $6^{-}$and $c d c$ mutant strains. $\mathrm{U}$ complex formation is dependent on SWI4 and SWI6 genes and on the completion of START /CDC28 gene function). U complex formation correlates with the transcriptionally active state of sRS2 in $c d c 4$ and $c d c 7$ mutants (lacZ RNA is present) but not with the transcriptionally inactive state in the $c d c 13$ and $c d c 15 \mathrm{mu}-$ tants (lacZ RNA is not detected), i.e., U complex is still present when sRS2 is not active as a UAS. address whether these complexes contain any other proteins in addition to SWI4 and SWI6.

Using the gel retardation assay, we have discovered two forms of SWI4-SWI6-DNA complexes that have different electrophoretic mobilities. The faster migrating $\mathrm{L}$ form can be detected in cell extracts from all stages of the cell cycle, whereas the slower $U$ form is absent in all forms of $G_{1}$ cells that have not yet undergone START. When cells treated with $\alpha$-factor are released from their $\mathrm{G}_{1}$ arrest, the $\mathrm{U}$ form appears with the same kinetics as $H O$ RNA. This raises the possibility that the STARTdependent activation of $H O$ transcription may be the result of a change in the physical state of SWI4-SWI6 complexes brought about by the activity of the CDC28 protein kinase.

\section{What activates HO transcription at START?}

Because START-specific activation of $\mathrm{HO}$ via multiple copies of a CACGA 4 motif within URS2 requires SWI6 (Breeden and Nasmyth 1987a), we have analyzed whether there are any changes in the state of the SWI6 protein as cells progress through the cell cycle, which might shed light on the mechanism of $\mathrm{HO}$ activation. Our first discovery, using the technique of in situ indirect immunofluorescence (Kilmartin and Adams 1984), is that the location of SWI6 changes during the cell cycle. SWI6 is concentrated in the nucleus during $G_{1}$ and $S$ phases but becomes distributed throughout the cytoplasm some time during $\mathrm{G}_{2}$ and only reaccumulates in the nucleus as cells complete mitosis. This implies that there may be a major change in the state of the SWI6 protein as cells enter $\mathrm{G}_{1}$. Although the change in SWI6 location may be necessary for $H O$ activation, it cannot be the actual trigger, because $H O$ is not activated until later in $\mathrm{G}_{1}$ when cells undergo START. Our observation raises the possibility that SWI6 might have a function (unrelated to $H O$ activation) during $\mathrm{G}_{1}$ prior to START.

Our second discovery concerning the state of SWI6 at different stages of the cell cycle may be more relevant to the triggering of $\mathrm{HO}$ activation. There are two types of complex formed between SWI4, SWI6, and CACGA ${ }_{4}^{-}$ 
containing oligonucleotides: $\mathrm{U}$ and $\mathrm{L}$ forms. The slower migrating $U$ complexes are cell cycle regulated and appear at the time of $H O$ activation. We propose that the formation of $\mathrm{U}$-type complexes on the $H O$ promoter may be the trigger that activates $H O$. This proposal is consistent with our observation that $U$ complexes were never detected in cells prevented from undergoing START (e.g., $c d c 28$ mutants, cells treated with $\alpha$-factor, and sizeselected $G_{1}$ cells) but are always formed in cells that have undergone START even though their subsequent cell cycle progression is arrested (e.g., cdc4 mutants that cannot initiate DNA replication but nevertheless express $H O$ ). $C D C 28$ is the only $C D C$ gene required for START /for which there are mutations with tight phenotypes) and is also the only one required for $U$ complex formation.

The timing of $U$ complex formation is consistent with its involvement in the activation of $H O$. HO RNA reaches half-maximal levels $65 \mathrm{~min}$ after $\alpha$-factor release, by which time $U$ complexes have also just formed $(60 \mathrm{~min})$. Because the appearance of $U$ complexes does not precisely coincide with the first appearance of $H O$ RNA ( $55 \mathrm{~min}$ ), it could be argued that these complexes may instead be involved in repression rather than activation of $H O$ transcription. This seems inconsistent with genetic data showing that SWI4 and SWI6 are activators of $H O$ transcription. Our inability to detect the formation of $U$ complexes at the precise time of the appearance of $H O$ RNA may simply be the result of a difference in the sensitivity of the two assays.

\section{What causes the formation of $U$ complexes?}

Because a very similar type of complex, the slightly faster migrating L complex, exists in cells before they undergo START, it is likely but not proven that $\mathrm{U}$ complexes arise from $\mathrm{L}$ complexes. In this case, understanding the physical difference between $\mathrm{U}$ and $\mathrm{L}$ complexes may be crucial to understanding what triggers $H O$ transcription. We have shown that both types of complex contain SWI4 and SWI6. We cannot yet exclude the possibility that the complexes contain other proteins in addition to SWI4 and SWI6. We think it likely that the complexes observed by Andrews and Herskowitz (1989b) on a similar but larger DNA fragment are equivalent to those described in this paper. Because we are only able to resolve $U$ from $L$ complexes under particular electrophoresis conditions, it is possible that the difference between the $U$ and $L$ complexes may be a subtle one, such as a conformational change induced by the modification of one of the constituent proteins, rather than the addition of a new protein.

Because the formation of $U$ complexes is dependent on the $C D C 28$ gene function, it is possible that the transition from the $\mathrm{L}$ to the $\mathrm{U}$ complex is caused by one of the proteins in the complex being phosphorylated by $\mathrm{CDC} 28$ protein kinase at the time of START. CDC28 is required not only for exit from $G_{1}$ but also for mitosis, and it is a strong possibility that it is active in one form or another throughout the $S, G_{2}$, and $M$ phases of the mitotic cycle, that is, throughout the entire period during which we can detect $U$ complexes. We have measured the level throughout the cell cycle of a CDC28-dependent histone $\mathrm{Hl}$ kinase that binds to the Schizosaccharomyces pombe Suc1 protein (Brizuela et al. 1987) but have found that this form of the kinase does not become active until well after the activation of $H O$ and the formation of $\mathrm{U}$ complexes. This implies that another form of the $C D C 28$ kinase /which either does not bind to Sucl or fails to recognize histone $\mathrm{Hl}$ as a substrate) must be responsible for $H O$ activation. Such a kinase may be formed by association of $C D C 28$ with $\mathrm{G}_{1}$-specific cyclins (Wittenberg et al. 1990).

\section{What inactivates HO transcription?}

Cell-cycle-regulated promoters must not only be activated but also repressed at specific stages during the cell cycle. The hypothesis that the cell cycle-dependent formation of $U$ complexes on URS2 triggers $H O$ activation cannot explain why the $H O$ promoter is inactivated soon after START because U complexes persist even until the end of mitosis, that is, long after $H O$ has been repressed. If our hypothesis concerning $\mathrm{HO}$ activation is correct, we must conclude that $H O$ is repressed by a mechanism that is not simply a reversal of its activation. One possibility is suggested by the behavior of another $\mathrm{HO}$ activator, SWI5. The location of the SWI5 protein is strongly cell cycle regulated (Nasmyth et al. 1990). The protein synthesized during $S$ or $\mathrm{G}_{2}$ accumulates in the cytoplasm and does not enter the nucleus until cells complete mitosis and enter $G_{1}$. It is possible, therefore, that an alteration of SWI5 following START might be sufficient to inactivate $H O$ in early S phase in the absence of any loss of active $U$ complexes at this time.

We have shown that the very same oligonucleotide sequence (sRS2) that will form U complexes throughout $\mathrm{G}_{2}$ and mitosis cannot activate transcription when cells are arrested at these stages of the cell cycle, even though its activation is independent of SWI5. Therefore, there must be another mechanism for $H O$ inactivation that involves SWI4 and SWI6. One possibility is that regulation of intracellular localization of SWI6 may be involved. SWI6, like SWI5, accumulates in the cytoplasm in cells blocked in $G_{2}$ or mitosis and there may be insufficient protein present in the nucleus for $\mathrm{HO}$ to remain active. Thus, the SWI4,6 U complexes that we detect in vitro may be of nuclear origin when isolated from $G_{1}$ cells but of cytoplasmic origin when isolated from $G_{2}$ cells. If this is so, $U$ complexes may only exist in the nucleus for a short period of time following START while SWI6 protein is still concentrated in the nucleus. Another mechanism for $H O$ repression is suggested by our observation that cell cycle mutants that fail to initiate DNA replication, for example, $c d c 4$ and $c d c 7$, also fail to inactivate $\mathrm{CACGA}_{4}$-dependent transcription. It is possible that DNA replication itself is necessary for the removal of active $U$ complexes from the $H O$ promoter. DNA replication per se could be a mechanism for the 
repression of transcription of certain cell cycle-regulated genes.

\author{
Materials and methods \\ Yeast strains \\ Y1268: MATa, leu2, trp1, ura3, prb1-1122, pep4-3, prc1-407, \\ gal2 (Shore et al. 1987) \\ Y699: MATa, ade2-1, trp1-1, can1-100, leu2-3 112, his3-11, \\ 15, GAL, si $^{+}$ \\ Y1052: MATa, ura3, swi4::LEU2 \\ Y1748: MATa, ade2-1, can1-100, leu2-3 112, his3-11, 15, \\ GAL, psi+, swi6::TRP1 \\ R1720: MATa, ade2-1, trp1-1, can1-100, leu2-3 112, his3-11, \\ 15, GAL, psi+, pep4::URA3 \\ R1355: Y1268 derivative, bar1::LEU2 \\ Y1719a: MATa, cdc28-4, can1-100, ura3 \\ R1719b: MATa, cdc28-4, can1-100, pep4::URA3 \\ Y1728a: MATa, hmla, HMRa, cdc15, HOXho229-102, ura3 \\ R1728b: MATa, hmla, HMRa, cdc15, HOXho229-102, \\ pep4::URA3 \\ Y1731a: MATa, $c d c 4-1$, ura3 \\ R1731b: MATa, cdc4-1, pep4::URA3 \\ Y1733a: MATa, $c d c 7-1$, ura3 \\ R1733b: MATa, cdc7-1, pep4::URA3 \\ Y1735a: MATa, cdc13, ura3 \\ R1735b: MATa, cdc13, pep4::URA3 \\ R1354: Y1268 derivative, swi6::TRP1 \\ R1071: MATa, HMLa, HMRa, swi4-100, ho/SUP4-O, HIS, \\ leu2, trp1, ade2-1, can1-100, pep4::URA3 \\ R1793: MATa, ade2-1, bar1::LEU2, can1-100, RP39/ \\ SWI5pro, ho, pep4::URA3
}

\section{Preparation of yeast extracts}

Stationary-phase cells grown in YEPD were used to inoculate (1:30 dilution) a fresh culture of the same medium and grown to an $\mathrm{OD}_{600}$ of 1.2-1.5. Cells were harvested, washed with cold distilled water, and broken by vortexing with $0.5-\mathrm{mm}$ glass beads for $3 \mathrm{~min}$. The breakage buffer contained $0.2 \mathrm{M}$ Tris- $\mathrm{HCl}$ (pH 8.0), $10 \mathrm{mM} \mathrm{MgCl}_{2}, 1 \mathrm{~mm}$ dithiothreitol (DTT), 10\% glycerol, $1 \mathrm{mM}$ PMSF, $0.5 \mathrm{~mm}$ TPCK, $25 \mu \mathrm{m}$ TLCK, $2 \mu \mathrm{g} / \mathrm{ml}$ of pepstatin A, $15 \mathrm{~mm} p$-nitrophenylphosphate, $0.1 \mathrm{~mm} \mathrm{Na-meta-}$ vanidate, $60 \mathrm{~mm}$ 2-glycerophosphate, and $50 \mathrm{~mm} \mathrm{NaF}$. Cell debris and glass beads were cleared from the suspension after a quick spin in the microcentrifuge. After another spin for 20 min, the crude extract was aliquoted, frozen immediately in liquid $\mathrm{N}_{2}$, and stored at $-70^{\circ} \mathrm{C}$.

\section{Probe for gel-retardation assay and specific competitors}

To detect specific formation of DNA-protein complexes on URS2 sequences, the oligonucleotides were synthesized by using an automated Applied Biosystems 380B DNA synthesizer. Oligonucleotides synthesized were sRS2 (from -443 to -358 bp of the 5'-upstream regulatory HO DNA); a 90-bp sequence containing the motifs CACGAAAT, TACGAAAT, CACGAAAA, and CGCGAAAA; an 80-bp sequence containing $5 \times$ TCGATCCACGAAAA (CACGA $)_{4}$; and a 53 -bp sequence containing the SWI5-binding site (Stillman et al. 1988). Oligonucleotides were used as competitors or probe. As probe, the radiolabeling was performed with Klenow enzyme and $\left[\alpha-{ }^{32} \mathrm{P}\right] \mathrm{CTP}$.

\section{Purification of SWI6 protein and raising of antibodies}

SWI6 was cloned previously in a $5.7-\mathrm{kb}$ HindIII-HindIII fragment (Breeden and Nasmyth 1987b). Oligonucleotide-directed mutagenesis in an M13 system (Zoller and Smith 1983) was used to generate an NdeI site at the initiation codon of the SWI6 reading frame. A $2.5-\mathrm{kb}$ fragment was derived from the construct, starting from the new NdeI site to the BgIII site that lies $\sim 200$ bp downstream of the terminating codon. This was cloned in the T7-RNA polymerase-inducible pRK171 a vector (McLeod et al. 1987) at the NdeI and BamHI sites and designated as T7-SWI6. The intact SWI6 protein was expressed and purified in the following manner: Competent BL21 (DE3) cells were transformed with T7-SWI6; one of the resulting ampicillin-resistant colonies was used to grow a 3-liter culture in $2 \times \mathrm{TY}$ medium with ampicillin to an $\mathrm{OD}_{600}$ reading of $0.6-0.8$. At this point, IPTG was added to the culture to a final concentration of $1 \mathrm{mM}$, inducing the expression of SWI6. Induction was allowed for $3 \mathrm{hr}$ before cells were spun down, washed, and resuspended in $20 \mathrm{ml}$ of lysis buffer consisting of $200 \mathrm{mM} \mathrm{KCl}, 20 \mathrm{mM}$ Tris (pH 7.5), $10 \mathrm{mM} \mathrm{MgCl}_{2}, 8 \mathrm{mg} / \mathrm{ml}$ of lysozyme, $1 \mathrm{mM} \mathrm{DTT}$, and $1 \mathrm{mM}$ PMSF. The resuspended cells were allowed to lyse on ice for $1 \mathrm{hr}$. After sonication, the lysis mixture was centrifuged at $45,000 \mathrm{rpm}$ for $1 \mathrm{hr}$. SWI6 is present in the supernatant /soluble fraction) at $>1 \%$ of the total soluble protein as determined by $7.5-20 \%$ gradient SDS-PAGE with Coomassie blue staining. The soluble fraction was dialyzed against $20 \mathrm{mM}$ Tris $(\mathrm{pH} 7.5)$ and $1 \mathrm{mM}$ DTT, and saturated ammonium sulfate was added to a concentration of $25 \%$. The mixture was incubated on ice for 2 $\mathrm{hr}$ and centrifuged as described previously. The supernatant was collected, and saturated ammonium sulfate was added to a final concentration of $40 \%$. Most of the SWI6 protein precipitates at this point and represents $\sim 50 \%$ of the total protein precipitated. After centrifugation, the pellet was resuspended in $2 \mathrm{ml}$ of 20 $\mathrm{mm}$ Tris (pH 7.5) and $1 \mathrm{~mm}$ DTT. After dialysis against the same buffer, the protein was loaded on a Fast Flow Q column and eluted against a $\mathrm{NaCl}$ gradient. SWI6 elutes at an estimated $75 \%$ homogeneity with a salt concentration of $\sim 0.25 \mathrm{M}$. The eluate was again dialyzed against $20 \mathrm{mM}$ Tris $(\mathrm{pH} 7.5)$ and $1 \mathrm{~mm}$ DTT and loaded onto a heparin-Sepharose column. With the same $\mathrm{NaCl}$ gradient, SWI6 elutes at $\sim 0.2 \mathrm{M}$ salt and has a homogenity of $\sim 95 \%$. After dialysis, as described previously, the eluate was used as antigen to raise antibodies against SWI6. Three rabbits were injected with $400 \mu \mathrm{g}$ of SWI6 with Freund's complete adjuvant as the initial immunization; 6 weeks later, a booster of $200 \mu \mathrm{g}$ of protein with Freund's incomplete adjuvant was used. Fourteen days later, test bleeds were taken, and all rabbits were found to have high titers of SWI6 antibodies.

\section{Immunoprecipitation assay}

To identify binding sites for the SWI6 protein on the HO gene promoter, an indirect immunoprecipitation assay was employed (McKay 1981). For each binding reaction $1 \mu l$ of polyclonal antiserum or a nonspecific antiserum was incubated with $20 \mu \mathrm{l}$ of protein A-Sepharose beads (Sigma) in $380 \mu \mathrm{l}$ of Ipp $_{500}[500 \mathrm{~mm} \mathrm{NaCl}, 10 \mathrm{mM}$ Tris-HCl $(\mathrm{pH} 8.0), 0.1 \% \mathrm{NP}-40$, and $0.1 \% \mathrm{NaN}_{3}$ ] on a rotating wheel at $4{ }^{\circ} \mathrm{C}$ for $90 \mathrm{~min}$. The beads were collected by centrifugation and washed twice with $300 \mu l$ of Ipp ${ }_{500}$ and twice with $400 \mu 1$ of $\operatorname{Ipp}_{50}$ (Ipp $_{50}$ is identical to Ipp ${ }_{500}$, except that it contains only $50 \mathrm{mM} \mathrm{NaCl}$ ). Binding reactions were set up as described below (gel-retardation assay) by using per reaction $75 \mathrm{ng}$ of pHO DNA (Nasmyth 1985b) digested to completion with either RsaI or Sau3AI and endlabeled using by T4 polynucleotide kinase and $\left[\gamma^{32} \mathrm{P}\right] \mathrm{ATP}$; the reactions were incubated on ice for $30 \mathrm{~min}$ before addition to 
the beads. Incubation was continued for an additional $10 \mathrm{~min}$, and the beads were then washed four times with $400 \mu l$ of $\operatorname{Ipp}_{50}$ (at $4^{\circ} \mathrm{C}$ ) and resuspended in $400 \mu \mathrm{l}$ of $\mathrm{HM}$ [ $300 \mathrm{~mm} \mathrm{NaCl}, 50 \mathrm{mM}$ Tris- $\mathrm{HCl}(\mathrm{pH} 7.4), 5 \mathrm{~mm}$ EDTA, $1.5 \%$ SDS, $1.5 \mathrm{mg} / \mathrm{ml}$ of proteinase $\mathrm{K}$ ]. Digestion was carried out at $37^{\circ} \mathrm{C}$ for $30 \mathrm{~min}$, and the supernatant was extracted with phenol-chloroform-isoamyl alcohol $(25: 24: 1)$. The DNA was recovered from the aqueous phase by ethanol precipitation following addition of $10 \mu \mathrm{g}$ of carrier RNA, dissolved in $5 \mu \mathrm{l}$ of loading buffer $180 \%$ formamide, $10 \mathrm{~mm} \mathrm{NaOH}, 1 \mathrm{~mm}$ EDTA, $0.1 \%$ bromophenol blue, $0.1 \%$ xylene cyanol bluel, denatured by boiling, and loaded onto a $6 \%$ acrylamide, $8.3 \mathrm{M}$ urea, $1 \times \mathrm{TBE}(\mathrm{pH} 8.3)$ gel.

Note that the experiments involving SWI4 antibodies in gelretardation assays were performed during the period of preparation of this manuscript. For this reason, we did not use them in the initial MacKay assays.

\section{Gel-retardation assay}

Band-shift assays were performed in $20-\mu l$ reactions in buffer containing $20 \mathrm{~mm}$ Tris- $\mathrm{HCl}$ (pH 7.5), $3 \mathrm{mM} \mathrm{MgCl} 2,50 \mathrm{~mm} \mathrm{NaCl}$, $1 \mathrm{~mm}$ DTT, $50 \mu \mathrm{g} / \mathrm{ml}$ of BSA, $0.1 \mathrm{~mm}$ EDTA, $5 \mathrm{~mm}$ spermidine, $5 \%$ glycerol, and $2-3 \mu \mathrm{g}$ of poly[d(I-C)]. Forty micrograms of total protein from yeast extracts was diluted in the buffer described above. After adding $\sim 0.03$ pmole of labeled probe, the reactions were incubated at room temperature for $15-20 \mathrm{~min}$ and loaded onto a $4 \%$ polyacrylamide gel (20:1 cross-linking) or $1.5 \%$ agarose gel in $0.5 \times \mathrm{TBE}$ buffer. In competition experiments, the competitors were added to 100 -fold molar excess (no difference was observed when competitors were added before, at the same time, or after the probe). When antibodies were used, $1 \mu \mathrm{l}$ of diluted antisera was added to the reaction mixture, and after $5 \mathrm{~min}$ of further incubation at room temperature the reaction mixture was loaded onto the gel. Polyacrylamide gels were prerun for $30 \mathrm{~min}$ at $130 \mathrm{~V}$ at $28-30^{\circ} \mathrm{C}$, and after loading the samples the same running conditions were used until the bromphenol blue had just passed the bottom of the gel $(\sim 1.5 \mathrm{hr})$. An alternative and possibly better means of resolving $U$ and $L$ complexes is to run longer gels with higher voltage so that the temperature in the gel reaches $28-30^{\circ} \mathrm{C}$. The prerun in this case is important for at least $1 \mathrm{hr}$ to equilibrate the temperature. Aga rose gels were run at $4^{\circ} \mathrm{C}$ for $1.5 \mathrm{hr}$. After fixing $(10 \%$ methanol, $10 \%$ acetic acid) and drying, the gels were exposed to autoradiography at $-80^{\circ} \mathrm{C}$.

\section{Other procedures}

S1 mapping analysis was performed as described by Nasmyth (1985a). Measurement of CDC28 Hl-kinase activity was as in Surana et al. (1991).

\section{Acknowledgments}

We thank Gustav Ammerer, Uttam Surana, and Adrian Bird for valuable and helpful discussions. Meinrad Busslinger and Gustav Ammerer are thanked for critical comments on the manuscript. We acknowledge Shantini Sockanathan for providing us with the SWI4-DHFR construct, Gottold Schaffner for the synthesis of the oligonucleotides, and Susan Gasser for sending us the pep4::URA3 plasmid used for gene disruption. We thank Brenda Andrews and Ira Herskowitz for kindly sending us the SWI4 antibodies and a plasmid containing the RP39 UAS. Ingeburg Hausmann and Hannes Tkadletz are thanked for the preparation of the figures. M.R.M.T. is a fellow of the Bra- zilian Conselho Nacional de Desenvolvimento Cientifico e Tecnologico-CNPq; G.T. and D.L. were EMBO fellows.

The publication costs of this article were defrayed in part by payment of page charges. This article must therefore be hereby marked "advertisement" in accordance with 18 USC section 1734 solely to indicate this fact.

\section{References}

Andrews, B. and I. Herskowitz. 1989a. Identification of a DNA binding factor involved in cell-cycle control of the yeast $\mathrm{HO}$ gene. Cell 57: 21-29.

. 1989b. The yeast SWI4 protein contains a motif present in developmental regulators and is part of a complex involved in cell-cycle dependent transcription. Nature 342: 830-833.

- Breeden, L. and K. Nasmyth. 1987a. Cell cycle control of the yeast $H O$ gene: Cis- and trans-acting regulators. Cell 48: $389-397$.

- $1987 \mathrm{~b}$. Similarity between cell-cycle genes of budding yeast and fission yeast and the Notch gene of Drosophila. Nature 329: 651-654.

Brizuela, L., G. Draetta, and D. Beach. 1987. pl3 ${ }^{\text {sucl }}$ acts in the fission yeast cell division as a component of the $\mathrm{p} 34^{\mathrm{cdc} 2}$ protein kinase. $E M B O$ J. 6: 3507-3714.

Haber, J.E. and K.B. Garvik. 1977. A new gene affecting the efficiency of mating type interconversion in homothallic strains of $S$. cerevisiae. Genetics 87: 33-50.

Hartwell, L.H. 1973. Synchronization of haploid yeast cell cycles, a prelude to conjugation. Exp. Cell Res. 76: 111-117.

- 1974. Saccharomyces cerevisiae cell cycle. Bacteriol. Rev. 38: 164-198.

Hawthorne, D.C. 1963. Directed mutation of the mating type alleles as an explanation of homothallism in yeast. Abstr. Proc. 11th Int. Congr. Genet. 7: 34-35.

Herskowitz, I. 1989. A regulatory hierarchy for cell specialization in yeast. Nature 342: 749-757.

Jacobs, C.W., A.E.M. Adams, P.J. Szaniszlo, and J.R. Pringle. 1988. Functions of microtubules in the Saccharomyces cerevisiae cell cycle. J. Cell Biol. 107: 1409-1426.

Jensen, R.E., G.F. Sprague, and I. Herskowitz. 1983. Regulation of yeast mating type interconversion: Feedback control of HO gene expression by the mating type locus. Proc. Natl. Acad. Sci. 80: 3035-3039.

Johnston, L.H., J.H.M. White, A.L. Johnson, G. Luccheni, and P. Plevani. 1987. The yeast DNA poll transcript is regulated in both the mitotic cell cycle and in meiosis and is also induced alter DNA damage. Nucleic Acids Res. 15: 5017-5030.

Kilmartin, J.V. and A.E. Adams. 1984. Structural rearrangements of tubulin and actin during the cell cycle of the yeast Saccharomyces. I. Cell Biol. 98: 922-933.

Lambert, S., H. Yu. J.T. Prchal, J. Lawler, P. Ruff, D. Speicher, M.C. Cheung, Y.W. Kan, and J. Palek. 1990. cDNA sequence for human erythocyte ankyrin. Proc. Natl. Acad. Sci. 87: 1730-1734.

Lydall, D., G. Ammerer, and K. Nasmyth. 1991. A new role for MCM1 in yeast: cell cycle regulation of SWI5 transcription. Genes \& Dev. (in press).

McKay, R.D.G. 1981. Binding of a Simian virus $40 \mathrm{~T}$ antigenrelated protein to DNA. J. Mol. Biol. 145: 471-488.

McLeod, M., M. Stein, and D. Beach. 1987. The product of the $\mathrm{mei}^{+}$gene, expressed under control of the mating-type locus, induces meiosis and sporulation in fission yeast. $E M B O$ J. 6: 729-736.

Nasmyth, K.A. 1983. Molecular analysis of a cell lineage. $\mathrm{Na}$ - 
ture 302: 670-676.

1985a. At least $1400 \mathrm{bp}$ of $5^{\prime}$ flanking DNA is required for correct expression of the $H O$ gene in yeast. Cell 42: 213 223.

1985b. A repetitive DNA sequence that confers cellcycle START(CDC28)-dependent transcription of the $\mathrm{HO}$ gene in yeast. Cell 42: 225-235.

Nasmyth, K. and D. Shore. 1987. Transcriptional regulation in the yeast life cycle. Science 237: 1162-1170.

Nasmyth, K., A. Seddon, and G. Ammerer. 1987. Cell cycle regulation of SWI5 is required for mother cell specific HO transcription in yeast. Cell 49: 549 .

Nasmyth, K., G. Adolf, D. Lydall, and A. Seddon. 1990. The identification of a second cell cycle control on the $H O$ promoter in yeast: Cell cycle regulation of SWI5 nuclear entry. Cell 62: 631-647.

Peterson, T., L. Prakash, S. Prakash, M.A. Osley, and S. Reed. 1985. Regulation of $C D C 9$, the $S$. cerevisiae gene that encodes DNA ligase. Mol. Cell. Biol. 5: 226-235.

Pringle, J.R. and L.H. Hartwell. 1981. The Saccharomyces cerevisiae cell cycle. In The molecular biology of the yeast Saccharomyces: Life cycle and inheritance (ed. J.N. Strathern et al.l, pp. 97-142. Cold Spring Harbor Laboratory, Cold Spring Harbor, New York.

Shore, D., D. Stillman, A.H. Brand, and K. Nasmyth. 1987. Identification of silencer binding proteins from yeast: Possible roles in SIR control and DNA replication. EMBO I. 6: 461467.

Sockanathan, S. 1991. "Characterization of SWI4: yeast cell cycle specific transcription," Ph.D. thesis. University of Cambridge, Cambridge, England.

Stern, M., R.E. Jensen, and I. Herskowitz. 1984. Five SWI genes are required for the expression of the $H O$ gene in yeast. $J$. Mol. Biol. 178: 853-868.

Stillman, D.J., A.T. Bankier, A. Seddon, E.G. Groenhout, and K. Nasmyth. 1988. Characterization of a transcription factor involved in mother cell specific transcription of the yeast $H O$ gene. EMBO I. 7: 485-494.

Storms, R.K., R.W. Ord, M.T. Greenwood, B. Mirdamadi, F.K. Chu, and M. Belfort. 1984. Cell-cycle dependent expression of thymidilate synthase in S. cerevisiae. Mol. Cell. Biol. 4: $2858-2864$.

Surana, U., H. Robtisch, C. Price, T. Schuster, I. Fitch, A.B. Futcher, and K. Nasmyth. 1991. The role of CDC28 and cyclins during mitosis in the budding yeast $S$. cerevisiae. Cell 65: 145-161.

White, J.H.M., S.R. Green, D.G. Baker, L.B. Dumas, and L.H. Johnston. 1987. The CDC8 transcript is cell cycle regulated in yeast and is expressed coordinately with $C D C 9$ and $C D C 21$ at a point preceding histone transcription. Exp. Cell. Res. 171: 223-231.

Winge, O. and C. Roberts. 1949. A gene for diploidization in yeast. C.R. Trav. Lab. Carlsberg Ser. Physiol. 24: 341-346.

Wittenberg, C., K. Sugimoto, and S.I. Reed. 1990. G1 specific cyclins of $S$. cerevisiae: Cell cycle periodicity regulation by mating pheromone and association with the $\mathrm{p} 34^{\mathrm{CDC} 28}$ protein kinase. Cell 62: 225-237.

Zoller, M.J. and M. Smith. 1983. Oligonucleotide-directed mutagenesis of DNA fragments cloned into M13 vectors. Methods Enzymol. 100: 468-500. 


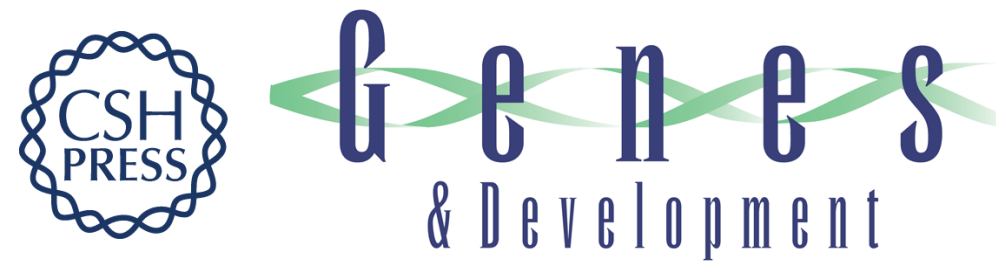

\section{Changes in a SWI4,6-DNA-binding complex occur at the time of $\mathrm{HO}$ gene activation in yeast.}

M R Taba, I Muroff, D Lydall, et al.

Genes Dev. 1991, 5:

Access the most recent version at doi:10.1101/gad.5.11.2000

References This article cites 33 articles, 9 of which can be accessed free at:

http://genesdev.cshlp.org/content/5/11/2000.full.html\#ref-list-1

License

Email Alerting

Service

Receive free email alerts when new articles cite this article - sign up in the box at the top right corner of the article or click here.

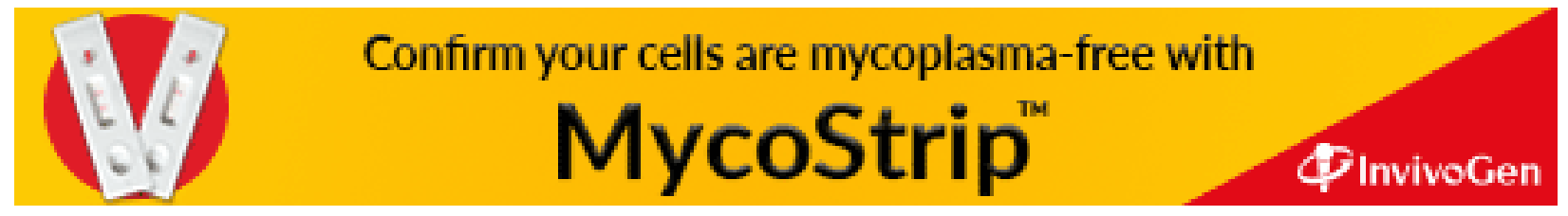

